\title{
Physical activity in chronic obstructive pulmonary disease: clinical impact and risk factors
}

\author{
Kyeong-Cheol Shin
}

Department of Internal Medicine, Yeungnam University College of Medicine, Daegu, Korea

Received: December 5, 2017

Accepted: December 10, 2017

\section{Correspondence to}

Kyeong-Cheol Shin, M.D. Department of Internal Medicine, Yeungnam University College of Medicine, 170 Hyeonchung-ro, Nam-gu, Daegu 42415, Korea

Tel: $+82-53-640-6683$

Fax: +82-53-654-3486

E-mail: shin1014@ynu.ac.kr

\section{See Article on Page 130-137}

Physical inactivity is common in patients with chronic obstructive pulmonary disease (COPD) compared with healthy control subjects [1], as well as in patients with other chronic diseases such as ischemic heart disease and rheumatoid arthritis [2]. In COPD, physical inactivity is not only a feature of advanced disease [3]; it is already reduced in the early stages of the disease, before onset of respiratory symptoms [4]. In a previous study, physical activity was reduced early in the course of the disease, and gradually decreased over time in COPD patients to a greater extent than in non-COPD subjects $[1,5]$.

Physical inactivity is an important predictor of COPD outcome. Lower levels of physical activity are associated with a higher risk of exacerbation and exacerbation-related hospitalization $[6,7]$, and also increase the risk of all-cause mortality in patients with COPD $[7,8]$. Thus, it is not surprising that physical activity maintained over time resulted in a protective effect against disease exacerbation and hospitalization. However, as physical activity decreased over time, the risk of exacerbation reached that of individuals who entered the study with low levels of physical activity and who maintained these low levels [9]. Therefore, a gradu- al decline in physical activity also predicts mortality. According to this study, the benefits of physical activity are not sustained over a long time period in COPD.

In COPD, physical activity is determined by several causes, including physiological, behavioral, social, and cultural factors [10]. In a cross-sectional study, decreased physical activity was associated with a decline in lung function, decreased heart function, systemic inflammation, and muscle weakness in patients with COPD [11,12]. Van Remoortel et al. [13] demonstrated that physical inactivity was more strongly associated with the presence of comorbidities than was airflow limitation. However, no prospective study has objectively assessed the association between physical activity and the presence of comorbidities over time in COPD. In a study by Watz et al. [14], physical activity was only weakly associated with lung function. However, there exists an inverse association between daily physical activity and dynamic hyperinflation [15], which is strongly correlated with the degree of exertional dyspnea [16]. In contrast to pulmonary function, lower extremity strength and exercise tests are associated with lower levels of physical activity in COPD patients [11,17], and daily symptoms such as dyspnea and fatigue are associated with physical 
activity levels [11,18]. Self-efficacy, defined as an individual's belief in their ability to be successful in something, is weakly associated with daily physical activity $[19,20]$. Moreover, impaired health status is somewhat correlated with physical activity, as confirmed in a 5-year longitudinal observational study.

In the current issue, Lee et al. [21] assessed physical activity in elderly patients with COPD and identified clinical factors associated with low levels of physical activity. This is the first study to analyze physical activity patterns and predictors of low-level physical activity in elderly patients with COPD. Patients older than 65 years were divided into three groups according to their level of physical activity (low, moderate, and high), and their health-related quality of life and levels of anxiety and depression were measured. The authors found that severe dyspnea and the presence of depression were independently associated with low-level physical activity. Unfortunately, this study is cross-sectional in nature; thus, the authors were unable to explain the causal relationship between low physical activity and the identified risk factors. A recent prospective study demonstrated that depression affects the rate of reduction of physical activity after 6 months in COPD patients [22]. Therefore, it is presumed that the results of the authors' study will be of clinical significance. Physical activity is usually self-reported and, unlike physical fitness, which is measured objectively, it tends to be overestimated. The 6-minute walk test is a widely used and validated test to measure physical fitness in COPD. To identify the risk factors that affect physical activity in clinical settings, it is necessary to develop a method that can easily measure physical fitness.

\section{Conflict of interest}

No potential conflict of interest relevant to this article was reported.

\section{REFERENCES}

1. Pitta F, Troosters T, Spruit MA, Probst VS, Decramer M, Gosselink R. Characteristics of physical activities in daily life in chronic obstructive pulmonary disease. Am J Respir Crit Care Med 2005;171:972-977.

2. Tudor-Locke C, Washington TL, Hart TL. Expected values for steps/day in special populations. Prev Med 2009;49:311.

3. Van Remoortel H, Hornikx M, Demeyer H, et al. Daily physical activity in subjects with newly diagnosed COPD. Thorax 2013;68:962-963.

4. Gouzi F, Prefaut C, Abdellaoui A, et al. Evidence of an early physical activity reduction in chronic obstructive pulmonary disease patients. Arch Phys Med Rehabil 2011;92:1611-1617.e2.

5. Vaes AW, Garcia-Aymerich J, Marott JL, et al. Changes in physical activity and all-cause mortality in COPD. Eur Respir J 2014;44:1199-1209.

6. Pitta F, Troosters T, Probst VS, Spruit MA, Decramer M, Gosselink R. Physical activity and hospitalization for exacerbation of COPD. Chest 2006;129:536-544.

7. Garcia-Rio F, Rojo B, Casitas R, et al. Prognostic value of the objective measurement of daily physical activity in patients with COPD. Chest 2012;142:338-346.

8. Waschki B, Kirsten A, Holz O, et al. Physical activity is the strongest predictor of all-cause mortality in patients with COPD: a prospective cohort study. Chest 2011;140:331-342.

9. Esteban C, Arostegui I, Aburto M, et al. Influence of changes in physical activity on frequency of hospitalization in chronic obstructive pulmonary disease. Respirology 2014;19:330-338.

10. Spruit MA, Pitta F, McAuley E, ZuWallack RL, Nici L. Pulmonary rehabilitation and physical activity in patients with chronic obstructive pulmonary disease. Am J Respir Crit Care Med 2015;192:924-933.

11. Waschki B, Spruit MA, Watz H, et al. Physical activity monitoring in COPD: compliance and associations with clinical characteristics in a multicenter study. Respir Med 2012;106:522-530.

12. Gimeno-Santos E, Frei A, Steurer-Stey C, et al. Determinants and outcomes of physical activity in patients with COPD: a systematic review. Thorax 2014;69:731-739.

13. Van Remoortel H, Hornikx M, Langer D, et al. Risk factors and comorbidities in the preclinical stages of chronic obstructive pulmonary disease. Am J Respir Crit Care Med 2014;189:30-38.

14. Watz H, Pitta F, Rochester CL, et al. An official European Respiratory Society statement on physical activity in COPD. Eur Respir J 2014;44:1521-1537.

15. Garcia-Rio F, Lores V, Mediano O, et al. Daily physical activity in patients with chronic obstructive pulmonary disease is mainly associated with dynamic hyperinflation. 
Am J Respir Crit Care Med 2009;180:506-512.

16. O'Donnell DE, Revill SM, Webb KA. Dynamic hyperinflation and exercise intolerance in chronic obstructive pulmonary disease. Am J Respir Crit Care Med 2001;164:770777.

17. Singh SJ, Puhan MA, Andrianopoulos V, et al. An official systematic review of the European Respiratory Society/ American Thoracic Society: measurement properties of field walking tests in chronic respiratory disease. Eur Respir J 2014;44:1447-1478.

18. Watz H, Waschki B, Meyer T, Magnussen H. Physical activity in patients with COPD. Eur Respir J 2009;33:262-272.

19. DePew ZS, Garofoli AC, Novotny PJ, Benzo RP. Screening for severe physical inactivity in chronic obstructive pulmonary disease: the value of simple measures and the validation of two physical activity questionnaires. Chron Respir Dis 2013;10:19-27.

20. Hartman JE, Boezen HM, de Greef MH, Ten Hacken NH. Physical and psychosocial factors associated with physical activity in patients with chronic obstructive pulmonary disease. Arch Phys Med Rehabil 2013;94:2396-2402.e7.

21. Lee SH, Kim KU, Lee H, Kim YS, Lee MK, Park HK. Factors associated with low-level physical activity in elderly patients with chronic obstructive pulmonary disease. Korean J Intern Med 2018;33:130-137.

22. Duenas-Espin I, Demeyer H, Gimeno-Santos E, et al. Depression symptoms reduce physical activity in COPD patients: a prospective multicenter study. Int J Chron Obstruct Pulmon Dis 2016;11:1287-1295. 